\title{
Extended-release morphine sulfate in treatment of severe acute and chronic pain
}

This article was published in the following Dove Press journal: Journal of Pain Research

18 September 2010

Number of times this article has been viewed

\author{
Robert J Balch \\ Andrea Trescot \\ Department of Anesthesiology \\ and Pain Medicine, University of \\ Washington, Seattle, WA USA
}

Correspondence: Andrea Trescot 4245 Roosevelt Way NE, Suite 40I, Seattle, WA 98195 , USA

Tel +l 2065984282

Fax +I 2065984596

Email uwpain@uw.edu
Abstract: Morphine is the archetypal opioid analgesic. Because it is a short-acting opioid, its use has been limited to the management of acute pain. The development of extended-release formulations have resulted in the increased utilization of morphine in chronic pain conditions. This review documents the history of morphine use in pain treatment, and describes the metabolism, pharmacodynamics, formulations, and efficacy of the currently available extended-release morphine medications.

Keywords: Morphine ER, sustained-release morphine, MSContin, Oramorph ${ }^{\circledR}, \operatorname{Kadian}^{\circledR}$, Avinza $^{\circledR}$, Embeda $^{\circledR}$

\section{Introduction}

Morphine was the first, and in many ways, the most important opioid used to treat acute and cancer pain. However, morphine is a short-acting medication, and the frequency of administration necessary to maintain adequate blood levels made it difficult to use this agent in the chronic setting. It was not until morphine was available in a long-acting formulation that it became used for chronic, noncancer pain. With once or twice a day dosing, steady-state blood levels can be achieved, compliance can be improved, and patients can sleep through the night. There should also, theoretically, be less reinforcement of drug misuse behavior, although that has never been proven.

\section{History}

Opioids have been used for their euphoric and analgesic properties for thousands of years. Records show that around $3400 \mathrm{BC},{ }^{1}$ the opium poppy was cultivated in lower Mesopotamia by the Sumerians, who referred to it as Hul Gil, the "joy plant". Ancient records indicate that it was also used by the Assyrians, Babylonians, and Egyptians. ${ }^{2}$ A German pharmacist, Frederick Wilhelm Adam Serturner, isolated morphine from opium in 1804 . He accomplished this by boiling the poppy plant and precipitating crystals from the water using ammonia, yielding a water-insoluble crystal. ${ }^{3}$ After ingesting the crystals, Serturner discovered that the compound induced a dreamlike state. Thus, in 1817, he named the compound "morphium" after Morpheus, the Greek god of dreams. ${ }^{4}$ Joseph Louis Gay-Lussac coined the term "morphine" later as a result of a German-French translation.

Although Serturner is known as the scientist who first isolated morphine, it was not until 1925 that Robert Robinson deduced the empiric formula, and in 1952 it was synthesized in the laboratory by Marshal T Cates, Jr. Nonetheless, it is Serturner who 
is now considered the "father of alkaloid chemistry", and his discovery is said to have marked the beginning of the "modern era of narcotics". 5 Serturner's early experiments proved that plants contain active substances that, on isolation, carry the "therapeutic properties of the plant"; it is no surprise, then, that the isolation of morphine, the first of such "natural products" was a "seminal event in the development of pharmacology as an independent discipline". ${ }^{3}$

Alkaloids are natural occurring, nitrogen-containing bases found in plants. Morphine is only one of 24 such alkaloids found within the resin of the opium poppy plant (Papaver somniferum), and comprises approximately 10\% of the total opium extract.

\section{Opioid receptors}

The term "opioid" is now used broadly to describe any compound that exerts activity at an opioid receptor. The opioid receptors were first discovered in $1972,{ }^{6}$ and the first endogenous opioid (enkephalin) was subsequently discovered in $1975 .^{7}$ The different opioid receptors include $\mathrm{Mu}-1$, $\mathrm{Mu}-2$, kappa, and delta. $\mathrm{Mu}$ receptors are found primarily in the brainstem and medial thalamus. Activation of these receptors can result in supraspinal analgesia, respiratory depression, euphoria, sedation, decreased gastrointestinal (GI) motility, and physical dependence. The subtype Mu-1 is mostly associated with analgesia, euphoria, and serenity, while $\mathrm{Mu}-2$ is related to respiratory depression, pruritus, prolactin release, dependence, anorexia, and sedation. Kappa receptors are found in the limbic and other diencephalic areas, brainstem, and spinal cord, and are responsible for spinal analgesia, sedation, dyspnea, dependence, dysphoria, and respiratory depression. Delta receptors are located largely in the brain and their effects are not well studied. Currently, activation of delta receptors is thought to be responsible for psychomimetic and dysphoric effects. ${ }^{8}$

These opioid receptors are G-linked proteins embedded in the cell membrane. When the opioid attaches to the receptor, the receptor is activated, releasing a portion of the $G$ protein, which diffuses within the cytoplasm until it reaches its target (either an enzyme or an ion channel). These targets alter protein phosphorylation via inhibition of cyclic AMP (cAMP), which acts as a second messenger within the cell, resulting in the activation of protein kinases (short-term effects) and gene transcription proteins and/or gene transcription (long-term effects), ${ }^{9}$ as shown in Figure 1.

Opioid receptors located on the presynaptic terminals of nociceptive $\mathrm{C}$ fibers and $\mathrm{A}$ delta fibers, when activated by

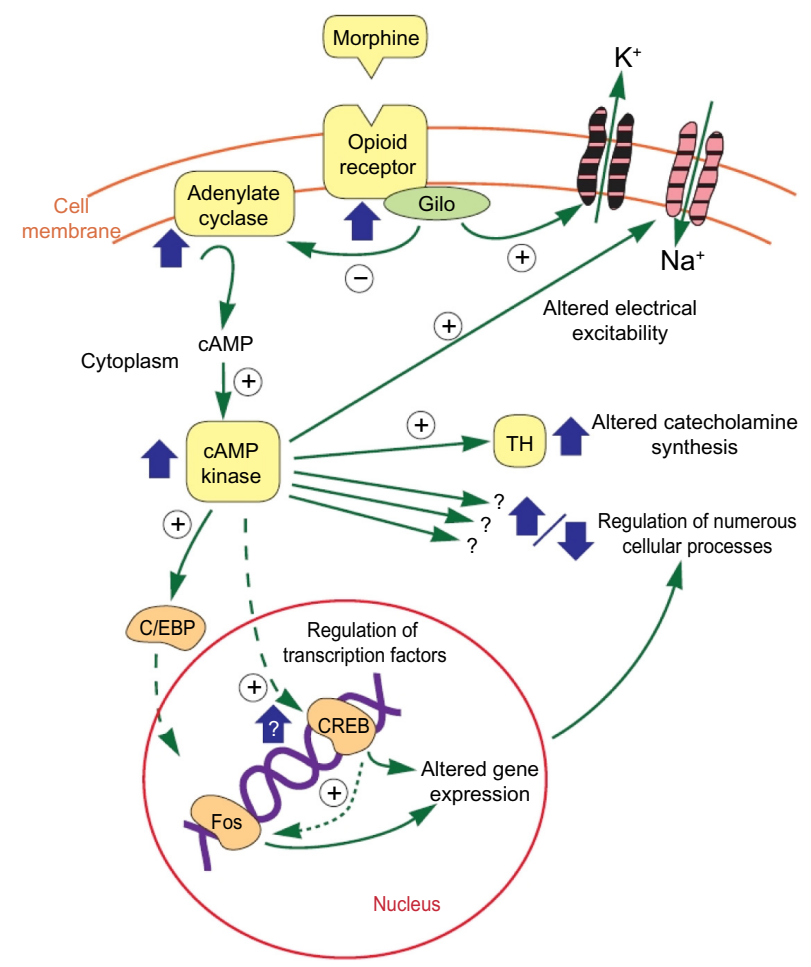

Figure I Opioid actions.

Notes: Copyright (c 2008, American Society of Interventional Pain Physicians. All rights reserved. Reproduced with permission from Trescot A, Datta S, Lee M, Hansen H. Opioid pharmacology. Pain Physician. 2008: I :SI33-SI53.

an opioid agonist, will indirectly inhibit voltage-dependent calcium channels, thereby decreasing cAMP levels and blocking the release of pain neurotransmitters such as glutamate, substance $\mathrm{P}$, and calcitonin gene-related peptide from the nociceptive fibers, resulting in analgesia (Figure 2). Opioids and endogenous opioids also activate presynaptic receptors on gamma aminobutyric acid (GABA) neurons, which inhibit the release of GABA in the ventral tegmental area ${ }^{10}$ (Figure 3). The inhibition of GABA allows dopaminergic neurons to fire more vigorously, and the extra dopamine in the nucleus accumbens is intensely pleasurable. ${ }^{11}$

\section{Structure}

The basic morphine compound in its raw form exists as a bitter, white crystalline compound that is water-insoluble. It is designated with the chemical formula $\mathrm{C}_{17} \mathrm{H}_{19} \mathrm{NO}_{3}$. Pharmaceutical-grade morphine exists as a salt, typically in the form of morphine hydrochloride, morphine acetate, or morphine sulfate (Figure 4).

\section{Pharmacodynamics}

Morphine has very poor lipid solubility, undergoes rapid conjugation with glucuronic acid, ionizes at physiologic $\mathrm{pH}$ 


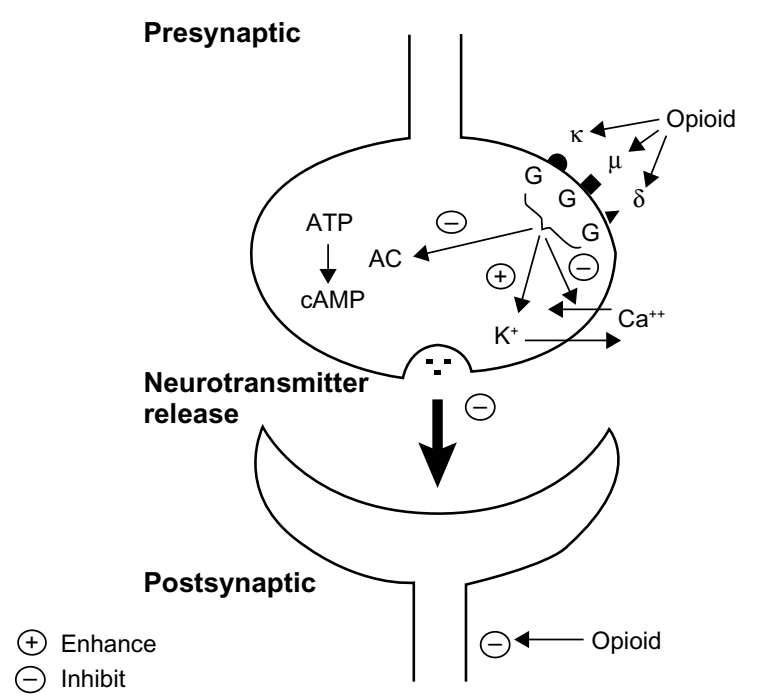

Figure 2 Opioid receptors.

Notes: Copyright (c) 2008, American Society of Interventional Pain Physicians. All rights reserved. Reproduced with permission from Trescot A, Datta S, Lee M, Hansen H. Opioid pharmacology. Pain Physician. 2008:I I:SI33-AI53.

and becomes highly protein-bound after oral administration. Thus, only $40 \%-50 \%$ of the originally administered oral dose reaches the central nervous system. It takes approximately 30 minutes for the immediate-release morphine formulation to reach the central nervous system, and 90 minutes for the extended-release formulation. ${ }^{12}$ The elimination half-life of morphine approximates 120 minutes. Only about $40 \%$ of the administered dose reaches the central compartment because of first-pass effect (ie, metabolism in the gut wall and liver). Once absorbed, morphine is distributed to skeletal muscle, kidneys, liver, intestinal tract, lungs, spleen, and brain. Morphine also crosses the placental membrane and has been found in breast milk.

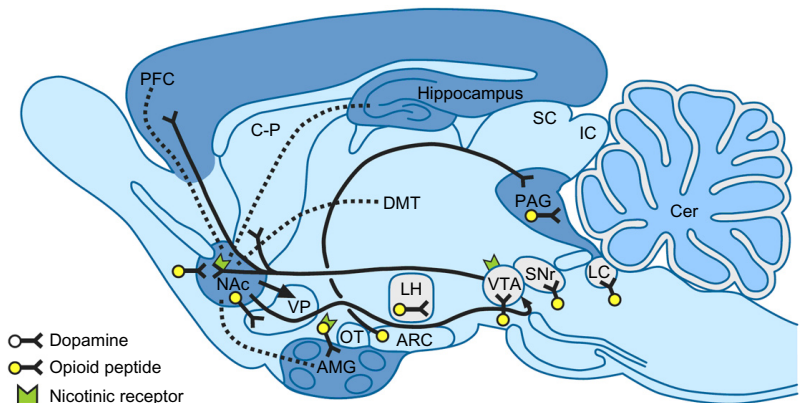

Figure 3 Opioid sites of action and addiction.

Notes: Copyright (C) 2008, American Society of Interventional Pain Physicians. All rights reserved. Reproduced with permission from Trescot A, Datta S, Lee M, Hansen H. Opioid pharmacology. Pain Physician. 2008:II (2 Suppl):SI33-SI53. Abbreviations: AMG, amydala; ARC, arcuate nucleus; CER, cerebellum; C-P, caudate putamen; DMT, dorsomedial thalamus; IC, inferior colliculus; LC; locus coeruleus; LH, lateral hypothalamus; Nac, nucleus accumbens; OT, olfactory tubercle; PAG, periaqueductal gray; PFC, frontal cortex; SC, superior colliculus; SNr, substantia nigra; VP, ventral pallidum; VTA, ventral tegmental area.

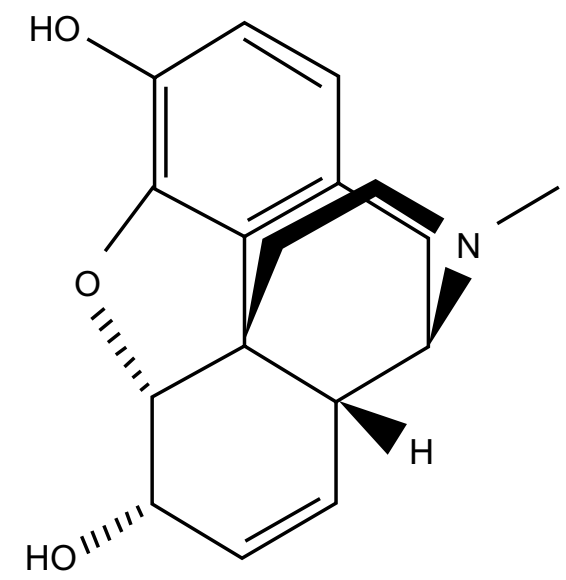

Figure 4 Morphine structure.

The nonalkalinized form of morphine crosses the bloodbrain barrier more readily than the alkalinized form. Alkalinization of the blood increases the fraction of nonionized morphine, thereby enhancing delivery to the central nervous system. ${ }^{8}$ One scenario where this is not the case is respiratory acidosis. During respiratory acidosis, brain concentrations of morphine increase because of increased cerebral blood flow secondary to higher carbon dioxide tension, which facilitates delivery of the nonionized form through the blood-brain barrier.

\section{Metabolism}

Glucuronidation of morphine occurs immediately after it is absorbed into the serum at both hepatic and extrahepatic sites. ${ }^{13}$ Glucuronidation produces morphine- 6 glucuronide (M6G) and morphine-3 glucuronide (M3G) in a ratio of $6: 1$. Approximately $5 \%$ of morphine is metabolized into normorphine by demethylation. ${ }^{8}$ Similar to the parent compound, M6G may provide additional analgesic effects. ${ }^{14}$ However, M3G is thought to lead to hyperalgesia in high concentrations. ${ }^{15}$ The first phase of morphine metabolism is carried out by the cytochrome $\mathrm{P} 450$ system and the second phase by the enzyme UGT2B7. The enzymes, CYP 3A4 and CYP2C8, are responsible for demethylation of morphine into normorphine. ${ }^{16}$ Morphine is also metabolized in small amounts to the drugs codeine and hydromorphone. ${ }^{8}$

\section{Side effect profile}

One of the most feared side effects of morphine is that of respiratory depression, with subsequent potential respiratory arrest. ${ }^{17}$ Direct respiratory depression is mediated by the effect of morphine on the nucleus accumbens in the brainstem, resulting in a decreased response to arterial carbon dioxide tension and a shift of the oxygen response curve to 
the right. Morphine also leads to decreased sympathetic tone, resulting in venous pooling and orthostatic hypotension. Effects on the GI and genitourinary systems include spasm of biliary smooth muscle, sphincter of Oddi spasm, decreased intestinal motility with constipation, direct stimulation of the chemotactic receptor trigger zone in the floor of the fourth ventricle resulting in nausea and vomiting, and spasm of the bladder trigone with urinary retention. Morphine is also associated with direct histamine release, which can lead to bronchospasm, hypertension, peripheral vasodilatation, flushing of the skin, and urticaria. ${ }^{8}$

\section{Addiction, tolerance, dependence, and opioid hyperalgia}

All opioids are associated with the risk of addiction, tolerance, dependence, and hyperalgia. Because opioids increase dopamine levels in the brain, they produce a pleasurable sensation, which is felt to be addictive. These dopamine centers are also the site of action of the addictive actions of alcohol, nicotine, and cocaine. ${ }^{8}$ Benyamin et $\mathrm{al}^{2}$ wrote that "Currently, statistics show that approximately $90 \%$ of patients with chronic pain receive opioids, and $90 \%$ of patients presenting to an interventional pain management center are already on opioids". McCleane and Smith ${ }^{9}$, in their review of opioids for persistent noncancer pain, describe that "with the increasing availability of modified strong opioid preparations, either in transdermal or oral formulations, and the increased advertising of their use by the pharmaceutical industry, there is an increased pressure to prescribe accompanied by an increased willingness to use opioids, particularly those that are classified as being strong". This has led to a dramatic increase in opioid prescribing, including extended-release morphine, with a concomitant increase in opioid poisonings and death. The benefit of analgesia, therefore, must always be balanced with the risk of addiction and overdose.

Tolerance, ie, loss of analgesic potency, leads to increasing dose requirements. The opioid receptors can become upregulated by continued exposure to the medication, or the enzymes controlling metabolism can be induced by prolonged exposure. ${ }^{2}$ Physical dependence is the development of an opioid withdrawal syndrome when the opioid is no longer attached to the receptors, and, unlike common conceptions, is not related to addiction. Hyperalgia (or hyperalgesia) is defined as increased pain sensitivity in the setting of an increased opioid dose. Opioid metabolites such as M3G may be involved; other etiologies include loss of GABA neurons to apoptosis, $N$-methyl $D$-aspartate
(NMDA) receptor agonism, and postsynaptic inhibition of spinal neurons. ${ }^{2}$

\section{Sustained-release morphine}

Morphine had a limited impact on medical science until the invention of the hypodermic needle by a Scottish physician, Alexander Wood, sometime between 1840 and $1850 .{ }^{4}$ The invention of the hypodermic needle escalated the use of morphine for control of pain, particularly during and after the American Civil War. The subsequent development of a commercially available oral form of morphine heralded the discipline of modern pain medicine as we now know it.

Major advances in the pharmacotherapy of chronic pain have led to the development of extended-release opioid delivery systems, thereby allowing less frequent dosing than the classic short-acting formulas. It is the patterns in serum drug levels that define the difference between short-acting opioids (SAO) and long-acting opioids (LAO); with SAOs, serum opioid levels rise rapidly following administration and then decline rapidly, while LAO administration allows for less fluctuation in serum opioid levels and an extended period within the therapeutic range. ${ }^{18}$ The assumption that plasma levels of opioids correspond to analgesia has led to the additional concept of minimum effective concentration, the plasma level of an opioid below which there is ineffective analgesia.

There are many proposed advantages of the long-acting formula compared with the short-acting formula. Several studies have suggested that modified-release opioids may result in fewer side effects than have been observed with short-acting opioids. ${ }^{19-21}$

The modified-release opioids have been preferred over the short-acting opioids because of the longer duration of action, which lessens the frequency and severity of endof-dose pain. ${ }^{22}$ Furthermore, it has been suggested that less frequent dosing leads to increased compliance and improved efficacy. ${ }^{23}$ Sustained analgesia and uninterrupted sleep are other potential advantages of the extended-release formulation compared with the short-acting variety. However, in a recent systematic review of long-acting versus short-acting opioids, ${ }^{24}$ Rauck noted that, while it was clear that long-acting opioids achieved more stable drug levels, there was no clear evidence from appropriately designed comparative trials to make a case for the use of one type of formulation over the other on the basis of clinical efficacy.

Several extended-release oral morphine formulations are now commercially available. The dose intervals recommended for these formulations vary from 8 to 12 to 24 hours. The 
most common formulations include MSContin ${ }^{\circledR}$, Oramorph $^{\circledR}$, Avinza $^{\circledR}$, and Kadian ${ }^{\circledR}$. MSContin, Oramorph ${ }^{\circledR}$, and Kadian ${ }^{\circledR}$ were originally developed for twice a day dosing, whereas Avinza ${ }^{\circledR}$ was developed for once-daily dosing. In this article, we will also briefly discuss Embeda ${ }^{\circledR}$, a new sustained-release morphine formulation combined with naltrexone as an abuse deterrent.

\section{MSContin twice a day}

MSContin (Purdue Pharma, Stamford, CT) was the first of the controlled-release tablet forms of morphine sulfate developed. The morphine sulfate in MSContin is contained in a dual-action polymer mix consisting of a hydrophilic polymer (hydroxypropyl methylcellulose) and a hydrophobic polymer (hydroxyethyl cellulose), cetostearyl alcohol, hypromellose, magnesium stearate, polyethylene glycol, talc, and titanium dioxide. ${ }^{25}$ During preparation of the system, the drug is blended with the hydrophilic polymer, selectively hydrated with a polar solvent, and fixed with a higher aliphatic alcohol. ${ }^{26}$ The partition coefficients of the active ingredient with the hydrophilic and hydrophobic components of the formulation control the release of drug from the tablet. ${ }^{27}$ The hydrophobic content is used to slow the diffusion of drug into the aqueous phase, which limits diffusion into the GI tract and absorption into the body. ${ }^{28}$ In other words, following administration, the gastric fluid dissolves the tablet surface and hydrates the hydrophilic polymer to produce a gel, the formation of which is controlled by the higher aliphatic alcohols. The rate of drug release from this formulation depends on the rate of diffusion of the dissolved morphine through the gel layer at the surface of the tablet. The depth of the gel layer increases over time as the gastric fluid gains access to the deeper regions of the tablet. The release rate can be controlled by varying the hydrophilic polymer, the type of hydrophobic matrix, or their ratio. ${ }^{29}$ MSContin is available as $15 \mathrm{mg}$, $30 \mathrm{mg}, 60 \mathrm{mg}, 100 \mathrm{mg}$, and $200 \mathrm{mg}$ tablets.

A suspension formula of MSContin is also available. In suspension, the morphine is attached to small beads of an ion exchange resin. Individual doses of the ion exchange resin are contained within a sachet, which must be reconstituted in water immediately before use to produce a suspension. Once administered, the sodium and potassium ions present in the GI tract fluid gradually displace morphine from the resin. Adding different amounts of the morphine-ion exchange resin complex to the sachet changes the dose delivered..$^{29}$ Lastly, there is a controlled-release rectal formulation that contains morphine, sodium alginate, and a calcium salt in a vehicle that melts in the rectum. The calcium salt cross-links with sodium alginate to form a high viscosity complex, which controls the rate of morphine dissolution and release..$^{29}$

\section{Oramorph ${ }^{\oplus}$ twice a day}

Oramorph $^{\circledR}$ (Xanodyne Pharmaceuticals, Newport, KY) sustained-release tablets contain morphine sulfate in a simple matrix system. This allows for morphine sulfate to be prepared in tablet form rather than a capsule. The drug and any additional ingredients (colloidal silicon dioxide, lactose, and stearic acid) are uniformly blended with a hydrophilic polymer, typically hydroxypropyl methylcellulose, and then compressed into biconvex tablets. ${ }^{30}$ After ingestion, GI fluid enters the tablet and hydrates the hydrophilic hydroxypropyl methylcellulose matrix, causing it to swell and form a viscous gel layer. The gel layer controls both the diffusion of water into the system and the diffusion of the drug out of the system. Over time, this layer begins to breakdown and dissolve. Once this occurs, water penetrates deeper into the matrix, forming a new viscous gel layer. This process continues until the entire hydrophilic matrix is dissolved. The gel matrix effectively traps the active ingredient and slows its release, which may occur by diffusion through the gel layer or erosion of the gel matrix itself. ${ }^{28}$ The medication is available in $30 \mathrm{mg}, 60 \mathrm{mg}$, and $100 \mathrm{mg}$ tablets.

\section{Kadian ${ }^{\circledR}$ once or twice a day}

$\operatorname{Kadian}^{\circledR}$ (Alpharma Pharmaceuticals, Piscataway, NJ) or $\operatorname{Kadian}^{\circledR}$, is a sustained-release formulation that places morphine sulfate in a capsule form by incorporating the drug into identical polymer-coated, sustained-release pellets contained in a hard gelatin capsule. ${ }^{31}$ The polymer coating consists of an insoluble ethylcellulose base along with polyethylene glycol and a methacrylic acid copolymer. Both the polyethylene glycol and the methacrylic acid copolymer are water-soluble, but the water solubility of the methacrylic acid copolymer is pH-dependent. After administration, the hard gelatin capsule shell quickly dissolves, releasing the drug-containing pellets. The acidity of the stomach causes the polyethylene glycol component of the polymer coating to start to dissolve, forming pores that allow GI fluid to enter the pellets and dissolve the morphine sulfate, which can then diffuse and be absorbed into the body. The pores are relatively small at this point, which limits drug diffusion. However, the dissolution of the polyethylene glycol component does allow for some drug to be absorbed quickly into the body (Figure 5). As the pellets enter and move through the intestines, the $\mathrm{pH}$ of the 


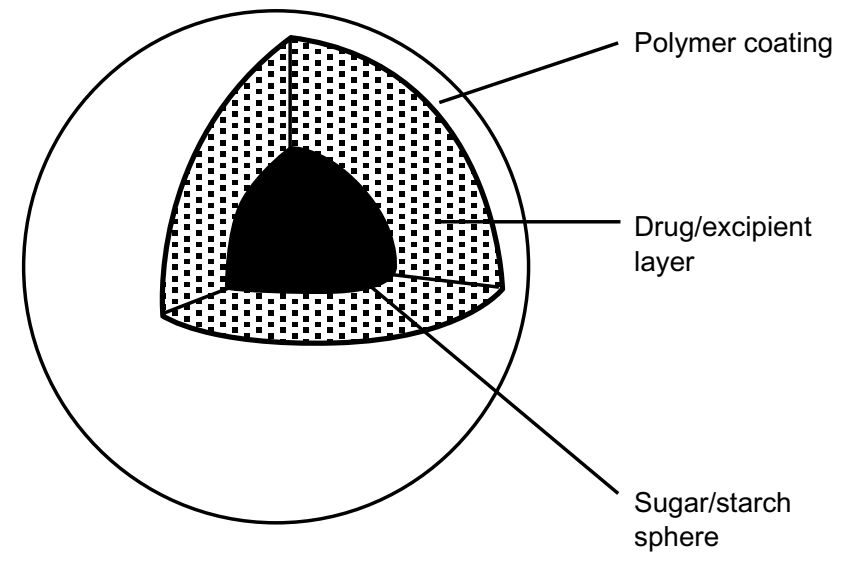

Figure 5 Pellet sustained-release formulation.

Notes: Copyright (c) 2006, Harvey Whitney Books Company. All rights reserved. Reproduced with permission from Amabile CM, Bowman BJ. Oral modifiedrelease opioid products for chronic pain management. Ann Pharmacother. 2006;40 (7-8): 1327-3135.

GI environment continues to increase, and the methacrylic acid copolymer begins to dissolve as the polyethylene glycol continues its dissolution. This process increases the number and size of the pores in the polymer coating, which increases the rate of morphine release. ${ }^{28}$ The medication is available in $10 \mathrm{mg}, 20 \mathrm{mg}, 30 \mathrm{mg}, 50 \mathrm{mg}, 60 \mathrm{mg}, 80 \mathrm{mg}$ $100 \mathrm{mg}$, and $200 \mathrm{mg}$ capsules, and can be administered once or twice a day.

\section{Avinza ${ }^{\circledR}$ once a day}

Avinza $^{\circledR}$ (King Pharmaceuticals, Bristol, TN) or AvinzaA ${ }^{\circledR}$, initially called Morphelan ${ }^{\circledR}$, is an extended-release oral morphine formulation that differs from the previous extended-release morphine formulations in that it was designed for once-daily dosing. The formulation contains a mixture of immediate-release and extended-release beads, approximately $1-2 \mathrm{~mm}$ in diameter, which release morphine in a time-dependent manner. ${ }^{32}$ The immediate-release component provides an initial rapid release of morphine, after which the extended-release component sustains therapeutic concentrations with minimal peak to trough fluctuation over a 24-hour dosing interval. The effect of the combination of these small beads, containing either immediate-release or extended-release morphine, is that plateau morphine concentrations can be achieved within 30 minutes, followed by maintenance of steady plasma concentrations throughout the 24-hour dosing interval. ${ }^{28,29}$ The extended-release beads are prepared using sugar/starch spheres upon which a drug/ excipient ("filler") layer is coated, followed by an ammoniomethacrylate copolymer coating. After administration and rapid dissolution of the hard gelatin capsule shell, the permeability of the ammonio-methacrylate copolymer coating allows GI fluid to enter the beads and solubilize the drug. The entrance of GI fluid is mediated by fumaric acid, which acts as an osmotic agent and local $\mathrm{pH}$ modifier within the drug/excipient layer. As a result, drug release is independent of the $\mathrm{pH}$ of the surrounding GI environment. After dissolving, morphine then diffuses out of the beads at a predetermined rate. This process prolongs the dissolution of the drug and extends its absorption into the body. The immediate-release beads are formed by utilizing the same sugar/starch core and drug/excipient layer, without the rate-limiting polymer coating, and contains approximately $10 \%$ of the extended-release dose. ${ }^{33}$ One important caveat is that dosing is limited to $1600 \mathrm{mg}$ per day or less due to fumaric acid-related renal toxicity. ${ }^{28}$ The medication is available in $30 \mathrm{mg}, 45 \mathrm{mg}, 60 \mathrm{mg}, 75 \mathrm{mg}, 90$ $\mathrm{mg}$, and $120 \mathrm{mg}$ capsules.

\section{Embeda ${ }^{\circledR}$}

A novel morphine formulation intended to deter abuse, Embeda $^{\circledR}$ (King Pharmaceuticals, Inc., Bristol, TN) or EmbedaA $^{\circledR}$ has just been approved for use in the US. In an effort to create a reduced abuse formulation, Embeda ${ }^{\circledR}$ was designed as pellets of an extended-release morphine sulfate formulation surrounding an internal core of naltrexone hydrochloride (an opioid receptor antagonist) in a ratio of 100:4 (morphine:naltrexone). The product is supplied as a gelatin capsule in dosages of $20 \mathrm{mg} / 0.8 \mathrm{mg}, 30 \mathrm{mg} / 1.2 \mathrm{mg}$, $50 \mathrm{mg} / 2 \mathrm{mg}, 60 \mathrm{mg} / 2.4 \mathrm{mg}, 80 \mathrm{mg} / 3.2 \mathrm{mg}$, and $100 \mathrm{mg} / 4 \mathrm{mg}$ (morphine sulfate/naltrexone hydrochloride). ${ }^{34}$ When these capsules are taken orally as directed, the naltrexone remains sequestered and should have no effect. However, chewing, pulverizing, or crushing the capsule or pellets would be expected to release the sequestered naltrexone, counter acting the effect of the morphine. Because of the pellet formulation, the capsules can be opened and sprinkled on apple sauce. One of the components of this drug is talc, so abusers who try to dissolve this pill for parenteral abuse may experience local tissue necrosis, infection, and other serious symptoms. ${ }^{34}$

\section{Discussion}

Once-or twice-daily extended-release morphine sulfate for the treatment of severe acute and chronic pain has many advantages over the use of the immediate-release formulation. The most obvious is convenience, which leads to improved patient compliance. Arkinstall et al ${ }^{35}$ devised a randomized, double-blind crossover trial comparing twice-daily dosing of sustained-release morphine versus 
immediate-release morphine at four-hourly intervals, and found that there was no statistical difference between pain relief, pain scores, breakthrough pain, or the amount of rescue medication taken. However, the patients demonstrated a strong preference for the twice-daily dosing as opposed to the four-hourly dosing, for reasons of convenience and ease of use.

Similarly, in a study by Ferrell et al, ${ }^{36}$ patients with cancer pain who had been treated with immediate-release morphine formulations were randomly assigned to either switch to MSContin or continue on their immediate-release formulation. The patients who had been switched to MSContin reported a lower pain intensity, improved strength, improved quality of life and better adjustment to disease and treatment than did the patients on the immediate-release morphine.

Patient preference for convenience was also clearly demonstrated in a study by Kerr and Tester ${ }^{37}$ in which patients taking $\operatorname{Kadian}^{\circledR}$ once daily reported pain scores and levels of interference with daily activities similar to those reported with MSContin twice daily, but there was a clear patient preference for Kadian ${ }^{\circledR}$ (55\%) over MSContin (33\%). Even though there was a statistically significant preference for once-daily dosing, there were no differences in pain control or tolerability between the two formulations. This suggests that the convenience of a once-daily versus twice-daily administration regimen may have been the cause of the clear patient preference for $\mathrm{Kadian}^{\circledR}$. One possible explanation for this preference is that immediate-release morphine requires repeat dosing throughout the day, causing the patient to focus attention on pain and pain management, whereas the sustained-release morphine allows the patient to focus on other aspects of life throughout the day. ${ }^{38}$

Another advantage of the sustained-release morphine formulation is that it results in a more stable serum concentration of the medication. With immediate-release morphine preparations, a steady state of serum morphine concentration is never obtained; the serum opioid levels rise rapidly following administration and then decline rapidly, leading to poor pain control and decreased function. The sustained-release formulations allow for less fluctuation in serum opioid levels and prolong serum concentration levels within the therapeutic range. ${ }^{18}$ Studies comparing the effect of immediate-release morphine versus sustained-release morphine on pain control have shown a correlation between serum opioid concentration levels and pain control. This suggests that serum opioid concentrations are directly proportional to the level of analgesia obtained. ${ }^{24,39}$
Currently, it is thought that measurable analgesia occurs when serum opioid concentrations exceed the minimum effective concentration and then analgesia falls once the serum concentration level is lower than the minimum effective concentration. ${ }^{29}$ Theoretically, sustained-release morphine formulations should maintain serum concentrations above the minimum effective concentration consistently, thereby providing more sustained pain relief without the need for repeated dosing. ${ }^{24}$ In fact, investigators have observed that in studies in which patients were taking modified-release opioids, the opioid daily dose remained stable over time. ${ }^{40}$ This may suggest that reduction in trough-peak fluctuation by using sustained-release morphine as opposed to immediaterelease morphine may influence the development of tolerance by either preventing it from occurring or by reducing the pace at which it develops.

Confirming this theory with future studies would strongly reinforce the advantages of sustained-release morphine over immediate-release formulations. However, it is important to note that the trough-peak fluctuation has not been confirmed by controlled trials, nor have these fluctuations been compared between the short- and long-acting opioids; this currently should not be the reason for choosing one morphine formulation over another.

Nonetheless, differences in peak-trough fluctuations have even been noted between the different sustainedrelease morphine formulations. In fact, in a study comparing Kadian $^{\circledR}$, Avinza ${ }^{\circledR}$, and MSContin, Kadian ${ }^{\circledR}$ and Avinza ${ }^{\circledR}$ had smaller trough-peak fluctuations compared with MSContin. ${ }^{41}$ However, these pharmacokinetic differences have not correlated with improved efficacy or pain control. ${ }^{41,42}$

An important implication derived from the studies measuring the pharmacokinetic differences between the different sustained-release morphine formulations is that sustained-release morphine formulations do not appear to be bioequivalent. A crossover study by Schobelock et $\mathrm{al}^{43}$ reinforced this implication by measuring mean time to peak concentration, mean peak concentration, and the mean and minimum serum concentrations at steady state of Oramorph ${ }^{\circledR}$ and MSContin. Oramorph ${ }^{\circledR}$ or MSContin $30 \mathrm{mg}$ was given every 12 hours for three days followed by a 14-day washout period before the alternative product was given. The mean time to peak concentration after Oramorph ${ }^{\circledR}$ was $3.75 \pm 1.21$ hours and after MSContin was $3.48 \pm 1.25$ hours. The mean peak concentration was $22.61 \pm 5.83 \mathrm{ng} / \mathrm{mL}$ for Oramorph ${ }^{\circledR}$ and $24.28 \pm 5.28 \mathrm{ng} / \mathrm{mL}$ for MSContin. The mean and minimum serum concentrations were $11.06 \pm 3.64 \mathrm{ng} / \mathrm{mL}$ for Oramorph ${ }^{\circledR}$ and $9.23 \pm 2.94 \mathrm{ng} / \mathrm{mg}$ for MSContin. Although the $\mathrm{t}$ of these 
two sustained-release morphine formulations were similar, they were by no means equivalent.

More recently, in an open-label study, ${ }^{44} 32$ patients with advanced cancer pain were randomized to receive MSContin or Oramorph ${ }^{\circledR}$ every 12 hours around the clock for five days, with immediate-release liquid morphine for rescue dosing. At the presumed morphine steady state (day 3), pain scores, as well as number and frequency of rescue doses, were consistently greater in the MSContin group (despite a higher median morphine dose in that group). There was a clinically important and directionally consistent trend that favored Oramorph ${ }^{\circledR}$, although not all values were statistically significant, and patient preference favored Oramorph ${ }^{\circledR}(P<0.05)$. Patients did not have difficulty swallowing either medication. The data suggested (but does not prove), by multiple clinically important measures, that Oramorph ${ }^{\circledR}$ may provide superior analgesic efficacy and less toxicity compared with MSContin. It also supports the concept that it cannot be assumed that different sustained-release formulations of a given opioid are clinically equivalent.

It has been hypothesized that reducing the peak-trough fluctuation in serum opioid concentration may decrease the risk of adverse events and periods of inadequate pain control. ${ }^{24,28}$ Most patients develop tolerance to these side effects, except for constipation. ${ }^{24}$ Nonetheless, it is possible that reduced fluctuation in serum morphine levels might enhance the development of tolerance to some adverse side effects. ${ }^{28}$ One important caveat is that, of the potential side effects from morphine use, respiratory depression appears to be quite dose-dependent. Thus, once tolerance to the lesser side effects develops, a more consistent opioid serum concentration should be sought so as to decrease the chance of dose-related respiratory depression, which lends further support to the use of sustained-release morphine over immediate-release morphine, especially in the management of a chronic condition. ${ }^{24}$

Additionally, sustained-release morphine has also been linked to improvement in quality of life and sleep. A longitudinal study of nursing home residents found greater improvements in functional parameters and social engagement when patients were treated with sustained-release morphine compared with immediate-release morphine. ${ }^{45}$ Rosenthal et $\mathrm{al}^{46}$ found that patients taking sustained-release opioids had improved objective sleep measures recorded by polysomnography, including reduced latency to rapid eye movement sleep, increased time spent in Stage 2 sleep and rapid eye movement sleep, improved sleep continuity, and reduced sleep latency to persistent sleep.
According to the information noted above, it appears that sustained-release morphine would be superior to immediaterelease morphine in the treatment of severe acute and chronic pain. However, there are no definitive studies to confirm this assumption, especially given that there are no large, multicenter, placebo-controlled head-to-head trials measuring the overall effectiveness of sustained-release morphine compared with immediate-release morphine specifically for the treatment of severe acute and chronic pain. In fact, it is important to note that one study found that there was no significant difference in pain scores between immediate-release morphine and sustained-release morphine. ${ }^{39}$ Similarly, studies comparing short-acting and long-acting oxycodone and tramadol found no evidence that the long-acting formula was better than the short-acting formula in improving pain control. ${ }^{47-49}$

Furthermore, there is a clear disadvantage of the sustained-release formulations in that they are very sensitive to conditions that alter their modified-release mechanisms. Therefore, most of these products must be swallowed whole and never broken, chewed, crushed or dissolved, due to the risk of rapid opioid release and absorption of potentially fatal doses. However, in patients with dysphagia, the entire capsule contents of Avinza ${ }^{\circledR}, \mathrm{Kadian}^{\circledR}$, or Embeda ${ }^{\circledR}$ can be sprinkled onto apple sauce immediately prior to administration. The prescribing information for Kadian ${ }^{\circledR}$ also indicates that the entire capsule contents may be administered through a 16 French gastrostomy tube. ${ }^{31}$

Sustained-release opioids should promote less addiction behavior by disconnecting the "pop-a-pill-feel-better" effect of immediate-release opioids, although this has never been proven. This risk of addiction is a serious national health issue; between 1992 and 2003, the US population increased by 14\%, while the number of people abusing controlled prescription drugs increased by $94 \%$, twice the increase in the number of people abusing marijuana, five times the number abusing cocaine, and 60 times the number abusing heroin. ${ }^{17}$

Embeda $^{\circledR}$, with its deterrent formulation, should also help decrease that risk; however, those studies have not yet been done. A pharmacodynamic study to evaluate the effect of naltrexone in the setting of crushed Embeda ${ }^{\circledR}$ used a randomized double-blind, triple-dummy, four-way crossover design to compare the effects of Embeda ${ }^{\circledR}$ whole and crushed with those of $120 \mathrm{mg}$ of immediate-release morphine and placebo, in 32 nondependent recreational opioid users. ${ }^{34}$ Overall, $87.5 \%$ of the subjects had some degree of reduced drugliking after receiving crushed Embeda ${ }^{\circledR}$, while $12.5 \%$ had no reduction in drug-liking. There was a considerable range 
in individual degrees of reduction in drug-liking, ranging between $10 \%$ and $50 \%$. Similarly, $9 \%$ of the subjects showed some degree of decreased euphoria with crushed Embeda ${ }^{\circledR}$ compared with immediate-release morphine. Meanwhile, the naltrexone in Embeda ${ }^{\circledR}$ does not appear to decrease analgesia. A multicenter, 12-month efficacy study ${ }^{50}$ of 465 opioidtolerant patients with chronic moderate to severe noncancer pain showed that more than $90 \%$ of the patients completing the study (162 of the original 465 patients) reported good-toexcellent global assessment of their pain relief. Most common adverse events were constipation (31.8\%), nausea (25.2\%), headache $(12.0 \%)$, and vomiting $(11.8 \%)$.

\section{Conclusion}

The American Pain Society ${ }^{22}$ states that the choice of opioid is based on the clinician's experience with an agent, because there are limited data supporting any preferred agent. Clinicians also base their choice of opioid on any patient's previous experience, given that some patients will tolerate or respond to particular agents better than others. An extended-release analgesic should provide around-theclock efficacy, result in fewer changes in drug plasma concentrations when compared with short-acting analgesics, provide maximal tolerability, and have minimal long-term adverse events with prolonged use. ${ }^{22}$ Currently, there are no overwhelming data supporting superior efficacy of any one of the once- or twice-daily dose, oral modified-release, or immediate-acting opioid products. ${ }^{28}$ However, the pharmacologic and pharmacodynamic properties of these formulations provide more convenient dosing intervals for patients and can achieve stable and sustained blood concentrations, theoretically leading to improved pain control when compared with the immediate-release formulations in the treatment of severe acute and chronic pain.

There is also no evidence that extended-release formulations decrease the risk of addiction, although the lack of rapid release and therefore lower overall blood levels is felt to disconnect the "pop-a-pill-feel-better" response of rapidonset medications. Until we have more studies, one must rely on sound clinical judgment and a risk/benefit assessment before initiating opioid treatment, while taking into account the current body of literature pertaining to this issue, the type of pain being treating, and the individuality of the patient.

\section{Disclosure}

The authors report no conflicts of interest in this work. In the past, AT has been on the speakers' bureau for Pfizer, Lilly,
Elan, Jansen, Alpharma, King, and Purdue, but is currently not lecturing for any pharmaceutical product.

\section{References}

1. Breasted JG. Ancient Records of Egypt. Chicago, IL: University of Chicago Press; 1930.

2. Benyamin R, Trescot AM, Datta S, et al. Opioid complications and side effects. Pain Physician. 2008;11:S105-S120.

3. Schwarz S, Huxtable R. The isolation of morphine. Mol Interv. 2001; 1:89-91.

4. The Role of Chemistry in History. Available from: http://itech.dickinson. edu/chemistry/?cat=107. Accessed in February, 2010.

5. Blakemore P, White J. Morphine, the proteus of organic molecules. Chem Commun (Camb). 2002;11:1159-1168.

6. Pert CB, Snyder SH. Opiate receptor: Its demonstration in nervous tissue. Science. 1973;179:1011-1014.

7. Hughes J, Smith T, Kosterlitz H, Fothergill L, Morgan B, Morris H. Identification of two related pentapeptides from the brain with potent opiate agonist activity. Nature. 1975;258:577-580.

8. Trescot A, Datta S, Lee M, Hansen H. Opioid pharmacology. Pain Physician. 2008:11:S133-S153.

9. McCleane G, Smith H. Opioids for persistent noncancer pain. Med Clin NAm. 2007;91:177-197.

10. Chahl LA. Opioids - mechanism of action. Aust Prescr. 1996;19: 63-65.

11. Nestler EJ. Molecular basis of long-term plasticity underlying addiction. Nat Rev Neurosci. 2001;2:119-128.

12. Stoelting RK. Pharmacology, Physiology and Anesthetic Practice. 2nd ed. Baltimore, MD: Lippincott Williams and Wilkins; 1991.

13. Hasslesstrom J, Sawe J. Morphine pharmacokinetics and metabolism in humans. Enterohepatic cycling and relative contribution of metabolites to active opioid concentrations. Clin Pharmacokinet. 2001;40: 344-354.

14. Lotsch J, Geisslinger G. Morphine-6-glucuronide: An analgesic of the future? Clin Pharmacokinet. 2001;40:485-499.

15. Donnelly S, Davis MP, Walsh D, Naughton M. Morphine in cancer pain management. Support Care Cancer. 2002;10:13-35.

16. Projean D, Morin PE, Tu TM, Ducharma J. Identification of CYP3A4 and $\mathrm{CYP} 2 \mathrm{C} 8$ as the major cytochrome P450s responsible for morphine N-demethylation in human liver microsomes. Xenobiotica. 2003;33:841-854.

17. Trescot AM, Boswell, MV, Atluri SL, et al. Opioid guidelines in the management of chronic non-cancer pain. Pain Physician. 2006;9:1-40.

18. McCarberg B, Barkin R. Long-acting opioids for chronic pain; pharmacotherapeutic opportunities to enhance compliance, quality of life, and analgesia. Am J Ther. 2001;8:181-186.

19. Kaplan R, Parris WC, Citron ML, et al. Comparison of controlledrelease and immediate-release oxycodone tablets AVINZA and chronic noncancer pain -263 inpatients with cancer pain. J Clin Oncol. 1998;16:3230-3237.

20. Caldwell JR, Hale ME, Boyd RE, et al. Treatment of osteoarthritis pain with controlled release oxycodone or fixed combination oxycodone plus acetaminophen added to nonsteroidal anti-inflammatory drugs: A double blind, randomized, multicenter, placebo controlled trial. J Rheumatol.1999;26:862-869.

21. Klepsted P, Kaasa S, Jystad A, Hval B, Borchgrevink PC. Immediate or sustained-release morphine for dose finding during start of morphine to cancer patients: A randomized, double-blind trial. Pain. 2003;101: 193-198.

22. American Pain Society. Principles of Analgesic Use in the Treatment of Acute Pain and Cancer Pain. Glenview, IL: American Pain Society; 2003.

23. Adams EH, Chwiecko P, Ace-Wagoner Y, et al. A study of AVINZA (morphine sulfate extended-release capsules) for chronic moderateto-severe noncancer pain conducted under real-world treatment conditions - The ACCPT Study. Pain Pract. 2006;6:254-264. 
24. Rauck RL. What is the case for prescribing long-acting opioids over short-acting opioids for patients with chronic pain? A critical review. Pain Pract. 2009;9:468-479.

25. MS Contin ${ }^{\circledR}$ (morphine sulfate). Package insert. Stamford, CT: Purdue Fredrick; 2004.

26. Leslie S. The Contin delivery system: Dosing considerations. J Allergy Clin Immunol. 1986;78:768-773.

27. Boroda C, Miller RB, Leslie ST, Nicol EG, Thomson I. Comparison of the bioavailability of aminophylline in a conventional base and in a continuous-release base. J Clin Pharmacol. 1973;13:383-387.

28. Amabile CM, Bowman BJ. Oral modified-release opioid products for chronic pain management. Ann Pharmacother. 2006;40: $1327-1335$

29. Gourlay GK. Sustained relief of chronic pain pharmacokinetics of sustained release morphine. Clin Pharmacokinet. 1998;35:173-190.

30. Oramorph ${ }^{\circledR}$ (morphine sulfate). Package insert. Newport, KY: Xanodyne Pharmaceuticals; 2006.

31. Kadian ${ }^{\circledR}$ (morphine sulfate). Package insert. Piscataway, NJ: Alpharma Pharmaceuticals; 2004.

32. Avinza ${ }^{\circledR}$ (morphine sulfate). Package insert. Bristol, TN: King Pharmaceuticals; 2008.

33. Semenchuk MR. Avinza. Curr Opin Invest Drugs. 2002;3:1369-72.

34. Embeda ${ }^{\circledR}$ (morphine sulfate). Package insert. Bristol, TN: King Pharmaceuticals; 2009.

35. Arkinstall WW, Goughnour BR, White JA, Stewart JH. Control of severe pain with sustained-release morphine tablets v. oral morphine solution. CMAJ. 1989;140:653-657, 661.

36. Ferrell B, Wisdom C, Wenzl C, Brown J. Effects of controlled-released morphine on quality of life for cancer pain. Oncol Nurs Forum. 1989;16: 521-526.

37. Kerr RO, Tester WJ. A patient preference study comparing two extendedrelease morphine sulfate formulations for cancer pain. Clin Drug Invest. 2000;19:25-32.

38. Vallerand $\mathrm{AH}$. The use of long-acting opioids in chronic pain management. Nurs Clin North Am. 2003;38:435-445.

39. Klepstad P, Kaasa S, Jystad A, Hval B, Borchgrevink PC. Immediate-or sustained-release morphine for dose finding during start of morphine to cancer patients: A randomized, double-blind trial. Pain. 2003;101: 193-198.

40. Roth SH, Fleisschmann RM, Burch FX, et al. Around-the-clock controlled-release oxycodone therapy for osteoarthritis-related pain: Placebo-controlled trial and long-term evaluation. Arch Intern Med. 2000;160:853-860
41. Portenoy RK, Sciberras A, Eliot L, et al. Steady-state pharmacokinetic comparisons of a new, extended-release, once-daily morphine formulation, AVINZA ${ }^{\circledR}$, and a twice daily controlled-release morphine formulation in patients with chronic moderate-to-severe pain. J Pain Symptom Manage. 2002;23:292-300.

42. Broomhead A, Kerr R, Tester W, et al. Comparison of a once-a-day sustained release morphine formulation with standard oral morphine. J Pain Symptom Manage. 1997;14:63-73.

43. Schobelock MJ, Shepard KV, Mosdell KW, et al. Multiple-dose pharmacokinetic evaluation of two formulations of sustained release morphine sulfate tablets. Curr Ther Res. 1995;56:1009-1021.

44. Homsi J, Walsh D, Lasheen W, et al. A comparative study of 2 sustainedrelease morphine preparations for pain in advanced cancer. Am J Hosp Palliat Care. 2010;27:99-105.

45. Won A, Lapane KL, Vallow S, Schein J, Morris JN, Lipsitz LA. Longterm effects of analgesics in a population of elderly nursing home residents with persistent nonmalignant pain. $J$ Gerontol A Biol Sci Med Sci. 2006;61:165-169.

46. Rosenthal M, Moore P, Groves E, et al. Sleep improves when patients with chronic OA pain are managed with morning dosing of once a day extended-release morphine sulfate $\left(\mathrm{AVINZA}^{\circledR}\right)$ : Findings from a pilot study. J Opioid Manag. 2007;33:145-154.

47. Caldwell JR, Hale ME, Boyd RE, et al. Treatment of osteoarthritis pain with controlled release oxycodone or fixed combination oxycodone plus acetaminophen added to nonsteroidal anti-inflammatory drugs: A double blind, randomized, multicenter, placebo controlled trial. J Rheumatol.1999;26:862-869.

48. Hale ME, Fleischmann R, Salzman R, et al. Efficacy and safety of controlled-release versus immediate-release oxycodone: Randomized, double-blind evaluation in patients with chronic back pain. Clin J Pain. 1999;15:179-183.

49. Bodalia B, McDonald CJ, Smith KJ, O’Brien C, Cousens L. A comparison of the pharmacokinetics, clinical efficacy, and tolerability of once-daily tramadol tablets with normal release tramadol capsules. J Pain Symptom Manage. 2003;25:142-149.

50. Webster LR, Brewer R, Sekora D, Morris D, Wang C, Stauffer J. Analgesic efficacy outcomes from a 12-month open-label safety study of morphine sulfate plus sequestered naltrexone $\mathrm{HCl}$ extended-release capsules (ALO-01) in patients with chronic, moderate-to-severe, nonmalignant pain. American Academy of Pain Medicine 25th Annual Meeting. January 28-31, 2009. Honolulu, HI.
Journal of Pain Research

\section{Publish your work in this journal}

The Journal of Pain Research is an international, peer-reviewed, open access, online journal that welcomes laboratory and clinical findings in the fields of pain research and the prevention and management of pain. Original research, reviews, symposium reports, hypothesis formation and commentaries are all considered for publication.

\section{Dovepress}

The manuscript management system is completely online and includes a very quick and fair peer-review system, which is all easy to use. Visit http://www.dovepress.com/testimonials.php to read real quotes from published authors. 